\title{
Use of Systemic Corticosteroids for Reasons Other than Asthma in Subjects with Asthma
}

\author{
Keisuke Watanabe Nobuyuki Horita Yu Hara Nobuaki Kobayashi \\ Takeshi Kaneko \\ Department of Pulmonology, Yokohama City University Graduate School of Medicine, Yokohama, Japan
}

\section{Keywords}

Asthma $\cdot$ Chronic rhinosinusitis · Collagen vascular disease ·

Corticosteroid $\cdot$ Malignancy

\begin{abstract}
Backgrounds: Recent studies have reported increased risks of adverse events from systemic corticosteroids even with only low-dose or short-term use. Some patients with asthma experience complications requiring systemic corticosteroids. However, few studies have examined issues associated with administration of systemic corticosteroids for reasons other than asthma among subjects with asthma. Objectives: We investigated patterns of systemic corticosteroid exposure for reasons other than asthma in subjects with asthma. Method: We retrospectively reviewed the records of adult subjects with asthma followed up for $>1$ year at Yokohama City University Hospital from January 1, 2010, to December 31, 2019. We investigated patterns and reasons for systemic corticosteroid use during follow-up. In addition, factors related to systemic corticosteroid use for reasons likely other than asthma were investigated. Results: Among the 568 subjects with asthma analyzed, 326 (57.4\%) had received systemic corticosteroids for some reason. Among
\end{abstract}

those 326 patients, 120 (36.8\%) had received systemic corticosteroids for reasons likely other than asthma. Multivariable analysis revealed rheumatoid arthritis, eosinophilic granulomatosis with polyangiitis, other collagen vascular diseases, chronic rhinosinusitis, and malignancy as positively associated with systemic corticosteroid exposure for reasons likely other than asthma in subjects with asthma. Conclusions: About $40 \%$ of systemic corticosteroid use in subjects with asthma was for reasons likely other than asthma. Clinicians should be aware of their asthma patients' exposures to systemic corticosteroids for nonasthma reasons, to avoid missing adverse events or underestimating the severity of asthma, and to reduce systemic corticosteroid use.

\section{(C) 2021 The Author(s)}

Published by S. Karger AG, Basel

\section{Introduction}

Asthma is characterized by eosinophilic airway inflammation, and inhaled corticosteroids are the key drug class for the treatment of this pathology. However, systemic corticosteroids are required for exacerbations and/ or maintenance in some cases of severe asthma [1]. About a quarter of subjects with asthma require short-term oral
(C) 2021 The Author(s)

Published by S. Karger AG, Basel

This is an Open Access article licensed under the Creative Commons Attribution-NonCommercial-4.0 International License (CC BY-NC) (http://www.karger.com/Services/OpenAccessLicense), applicable to the online version of the article only. Usage and distribution for commercial purposes requires written permission. 


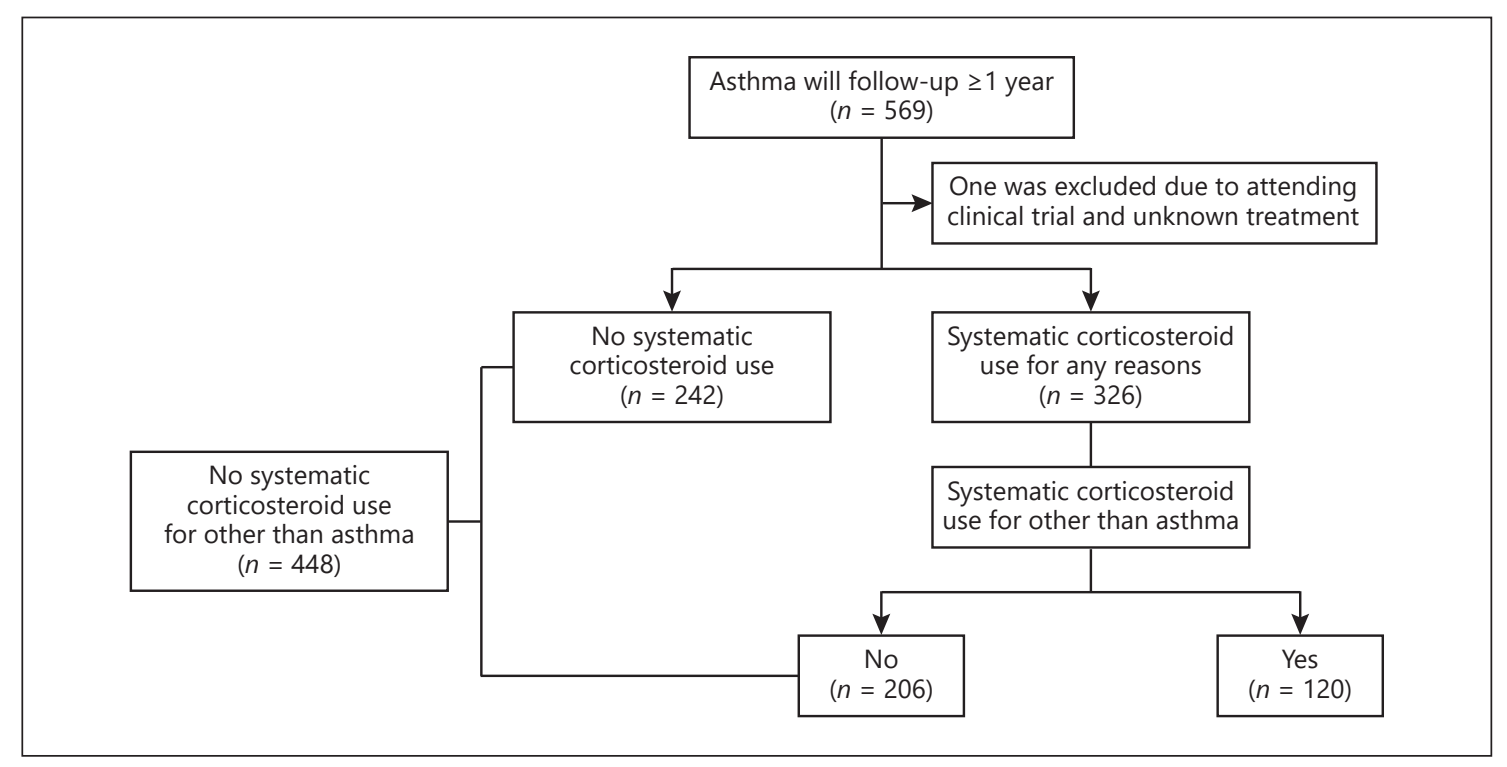

Fig. 1. Flow diagram for the study.

corticosteroids (OCS) during a 1-year period, and 20$60 \%$ of patients with severe or uncontrolled asthma are on long-term oral/systemic corticosteroids [1]. Recent studies have reported an increased risk of adverse events from systemic corticosteroids even among individuals with low-dose and/or short-term use of these drugs [1-6]. Clinicians therefore need to attend to their patients' exposures to systemic corticosteroids. Some asthmatic patients develop complications requiring systemic corticosteroids. However, few studies have examined exposures to systemic corticosteroids for reasons other than asthma in subjects with asthma. We therefore investigated patterns of systemic corticosteroid exposure for reasons likely other than asthma in subjects with asthma.

\section{Materials and Methods}

We retrospectively reviewed the electronic medical chart of adult subjects ( $\geq 18$ years old) with physician-diagnosed asthma who were followed up for $>1$ year at outpatient clinic of Yokohama City University Hospital from January 1, 2010, to December 31, 2019. We then investigated patterns and reasons for systemic corticosteroid use during follow-up. We compared subjects with and without systemic corticosteroid use for reasons likely other than asthma. Factors related to systemic corticosteroid use for reasons likely other than asthma were also investigated. The dose of systemic corticosteroid was categorized as low (prednisolone-equivalents $\leq 5 \mathrm{mg} /$ day) or high (prednisolone-equivalents $>5 \mathrm{mg} /$ day). Duration of systemic corticosteroid use was categorized as short ( $\leq 3$ months) or long ( $>3$ months). Systemic corticosteroids included oral, intravenous, and intramuscular corticosteroids. We col- lected the data of spirometry, peripheral eosinophils, and total IgE at the stable state of asthma within 2 years before or after the start of the study period. Specific IgE status at the diagnosis and/or during follow-up was also collected.

Data are presented as mean (range) unless otherwise specified. JMP version 11 software (SAS Institute, Cary, NC, USA) was used for statistical analyses. Comparisons were made using the MannWhitney $U$ test for continuous variable, while categorical variables were compared using Pearson's $\chi^{2}$ test or Fisher's exact test. To detect factors related to systemic corticosteroid exposure for reasons likely other than asthma, we performed multivariate analysis by logistic regression analysis for factors showing values of $p<0.1$ in univariate analysis. Statistical significance was defined as a value of $p<0.05$, and all tests were 2-tailed.

This study was approved by the institutional review board at Yokohama City University Hospital (approval no. B200500001). Due to the retrospective nature of this study, the need to obtain written informed consent was waived.

\section{Results}

Figure 1 shows the flow diagram for the study. A total of 569 subjects with asthma were followed up for $>1$ year. One subject was excluded because of attending a clinical trial and receiving unknown treatment. Thus, data from 568 subjects with asthma were analyzed, revealing that 326 of the 568 patients $(57.4 \%$; $95 \%$ confidence [CI]: $53.3-61.4 \%)$ received systemic corticosteroids for any reason. Among those 326 subjects, 120 patients (36.8\%; 95\% CI: 31.8-42.2\%) received at least 1 dose of systemic corticosteroid for reasons likely other than asthma. Ta- 
Table 1. Characteristics of asthma in the population

\begin{tabular}{|c|c|}
\hline & $N=568$ \\
\hline Asthma onset at $<20$ years old, $n(\%)$ & $121(23.0)(n=527)$ \\
\hline Allergic asthma, ${ }^{*} n(\%)$ & $255(40.1)$ \\
\hline Eosinophils in peripheral blood & $(n=505)$ \\
\hline Eosinophil ratio, $n(\%)$ & $3.4(0-33.4)$ \\
\hline Absolute number (cells/ $\mu \mathrm{L})$ & $216(0-2,347)$ \\
\hline Total IgE, IU/mL & $216(1-81,189)(n=284)$ \\
\hline Lung function & $(n=364)$ \\
\hline FVC, L & $2.78(0.95-6.48)$ \\
\hline FEV1, L & $1.99(0.48-4.37)$ \\
\hline FEV1/FVC, $n(\%)$ & $71.7(27.56-94.48)$ \\
\hline FEV1\% predicted & $87.9(21-156.8)$ \\
\hline GINA treatment step $^{\dagger, \ddagger}(1 / 2 / 3 / 4 / 5)$ & $25 / 87 / 96 / 222 / 138$ \\
\hline \multicolumn{2}{|l|}{ Medication, ${ }^{\dagger} n(\%)$} \\
\hline ICS & $539(94.9)$ \\
\hline LABA & $379(66.7)$ \\
\hline LAMA & $55(9.7)$ \\
\hline LTRA & $187(32.9)$ \\
\hline Theophylline & $119(21.0)$ \\
\hline
\end{tabular}

Data are presented as median (range) or patients $n$ (\%). FEV1, forced expiratory volume in $1 \mathrm{~s}$; FVC, forced vital capacity; ICS, inhaled corticosteroid; LABA, long-acting $\beta 2$ agonist; LAMA, long-acting anticholinergic agent; LTRA, leukotriene receptor antagonist. * Allergic asthma was defined as having at least one positive result of specific IgE and/or symptom with exposure to allergens. Allergens associated with asthma [7] are listed in supplementary. ${ }^{\dagger}$ GINA treatment step and medication at the start of the study periods. ${ }^{\ddagger}$ Oral corticosteroids used for reasons other than asthma were not included in evaluating the treatment step of asthma.

ble 1 shows the characteristics of asthma in this population.

Table 2 shows a comparison of the subjects with or without systemic corticosteroid exposure for reasons likely other than asthma. Subjects receiving systemic corticosteroids for reasons likely other than asthma were older (64 years [22-84 years] vs. 59 years [21-88 years]; $p=$ $0.020)$ and more frequently showed rheumatoid arthritis (RA) $(7.5 \%$ vs. $2.9 \% ; p=0.031)$, eosinophilic granulomatosis with polyangiitis (EGPA) $(5.8 \%$ vs. $0.5 \% ; p<0.001)$, other collagen vascular diseases (CVDs) $(20.8 \%$ vs. $1.8 \%$; $p<0.001)$, chronic rhinosinusitis (CRS) $(21.7 \%$ vs. $7.8 \%$; $p<0.001)$, and malignancy ( $10.0 \%$ vs. $2.0 \%$; $p<0.001)$.

Table 3 shows the causes requiring systemic corticosteroid use for reasons likely other than asthma. Main likely reasons for nonasthma use of systemic corticosteroids were RA ( $n=9,7.5 \%)$, EGPA $(n=7,5.8 \%)$, other CVD $(n=24,20 \%)$, CRS $(n=20,16.7 \%)$, and malignancy $(n=12,10.0 \%)$.

Systemic Corticosteroids in Asthma
Table 4 shows factors related to systemic corticosteroid exposure for reasons likely other than asthma in subjects with asthma according to multivariable analysis. Age (odds ratio [OR] 1.02, 95\% CI: 1.00-1.04; $p=0.033$ ), duration of follow-up (OR 1.13, 95\% CI: 1.05-1.22; $p=$ 0.001 ), RA (OR $3.42,95 \%$ CI: $1.30-8.98 ; p=0.017$ ), EGPA (OR 32.6, 95\% CI: 6.31-168; $p<0.001$ ), other CVD (OR 22.8, 95\% CI: 9.04-52.3; $p<0.001$ ), CRS (OR 4.97, 95\% CI: $2.64-9.36 ; p<0.001$ ), and malignancy (OR 8.56, 95\% CI: $3.15-23.2 ; p<0.001)$ were positively associated with systemic corticosteroid exposure for reasons likely other than asthma in subjects with asthma.

\section{Discussion}

In this study, $57.4 \%$ of subjects with asthma received systemic corticosteroids during follow-up (median, 4.1 years). Of these, $36.8 \%$ received systemic corticosteroids for reasons likely other than asthma management. Factors identified as positively related to systemic corticosteroid use for reasons likely other than asthma were age, RA, EGPA, other CVD, CRS, and malignancy.

Systemic corticosteroid use is related to a wide variety of adverse events, even in low doses or with intermittent use [1-6]. Moreover, systemic corticosteroids for reasons other than asthma could contribute to better asthma control and clinician underestimation of the severity of the asthma. Clinicians should be aware of systemic corticosteroid use for reasons other than asthma, to ensure that adverse events are not missed and the severity of asthma is correctly evaluated.

As mentioned above, with the increasing evidence of adverse events following low-dose or intermittent use of systemic corticosteroids, reducing systemic corticosteroid use is increasingly being recognized as important. In recent studies, OCS use for asthma is relatively common, and the proportion of OCS was stable during the study periods [8-10]. However, reducing systemic corticosteroids administered for asthma is insufficient, as $36.8 \%$ of subjects with asthma received systemic corticosteroids, which uses other than asthma. This indicates the importance of reducing the use of systemic corticosteroids for reasons other than asthma. To achieve this goal, one target is the comorbidity of allergic diseases. The incidence of concomitant asthma and other allergic diseases is high $[11,12]$. In addition, some treatments are effective against both asthma and other allergic diseases [13-16]. Total management of allergic diseases is thus important to reduce systemic corticosteroid exposure. In this study, 
Table 2. Comparison of clinical features

\begin{tabular}{|c|c|c|c|}
\hline & $\begin{array}{l}\text { Systemic corticosteroid } \\
\text { use for reasons likely other } \\
\text { than asthma }(n=120)\end{array}$ & $\begin{array}{l}\text { No systemic corticosteroid } \\
\text { use for reasons likely other } \\
\text { than asthma }(n=448)\end{array}$ & $p$ value \\
\hline Age, years & $64(22-84)$ & $59(21-88)$ & 0.020 \\
\hline Sex (male/female) & $40 / 80$ & $195 / 253$ & 0.048 \\
\hline Smoking history (ex/never/current) & $67 / 36 / 15(n=118)$ & $240 / 137 / 57(n=434)$ & 0.960 \\
\hline Follow-up, years & $4.5(1.0-10.0)$ & $3.9(1.0-10.0)$ & 0.051 \\
\hline GINA treatment step*, ${ }^{\dagger}(1 / 2 / 3 / 4 / 5)$ & $8 / 14 / 20 / 41 / 37$ & $17 / 73 / 76 / 181 / 101$ & 0.151 \\
\hline Systemic corticosteroid use for asthma, $n(\%)$ & $53(44.1)$ & $209(46.7)$ & 0.680 \\
\hline Exacerbation & $50(41.7)$ & $196(43.8)$ & 0.756 \\
\hline Maintenance & $4(3.3)$ & $17(3.8)$ & 1 \\
\hline \multicolumn{4}{|c|}{ Systemic corticosteroid use for nonasthma, $n(\%)$} \\
\hline Long term, $>5 \mathrm{mg}$ & $45(37.5)$ & & \\
\hline Long term, $\leq 5 \mathrm{mg}$ & $49(40.1)$ & & \\
\hline Short term, $>5 \mathrm{mg}$ & $35(29.2)$ & & \\
\hline Short term, $\leq 5 \mathrm{mg}$ & $24(20.0)$ & & \\
\hline \multicolumn{4}{|l|}{ Comorbidities, $n(\%)$} \\
\hline COPD & $7(5.8)$ & $47(10.5)$ & 0.160 \\
\hline \multicolumn{4}{|l|}{ CVD } \\
\hline RA & $9(7.5)$ & $13(2.9)$ & 0.031 \\
\hline EGPA & $7(5.8)$ & $2(0.5)$ & $<0.001$ \\
\hline Other & $25(20.8)$ & $8(1.8)$ & $<0.001$ \\
\hline Allergic rhinitis & $22(18.3)$ & $118(26.3)$ & 0.075 \\
\hline CRS & $26(21.7)$ & $35(7.8)$ & $<0.001$ \\
\hline Cardiovascular diseases & $11(9.2)$ & $38(8.5)$ & 0.855 \\
\hline Hypertension & $31(25.8)$ & $88(19.6)$ & 0.164 \\
\hline Gastrointestinal diseases & $5(4.2)$ & $19(4.2)$ & 1 \\
\hline Liver diseases & $6(5.0)$ & $23(5.1)$ & 1 \\
\hline Kidney diseases & $8(6.7)$ & $14(3.1)$ & 0.105 \\
\hline Neuromuscular diseases & $5(4.1)$ & $14(3.1)$ & 0.570 \\
\hline Diabetes & $15(12.5)$ & $47(10.5)$ & 0.513 \\
\hline Endocrine diseases & $9(7.5)$ & $19(4.2)$ & 0.155 \\
\hline Hematological diseases & $0(0)$ & $4(0.9)$ & 0.584 \\
\hline Malignancy & $12(10.0)$ & $9(2.0)$ & $<0.001$ \\
\hline Atopic dermatitis & $4(3.3)$ & $33(7.4)$ & 0.144 \\
\hline Psychological diseases & $9(7.5)$ & $39(8.7)$ & 0.853 \\
\hline \multicolumn{4}{|c|}{$\begin{array}{l}\text { Data are presented as median (range) or patients } n(\%) \text {. COPD, chronic obstructive pulmonary disease; CR } \\
\text { chronic rhinosinusitis; CVD, collagen vascular disease; EGPA, eosinophilic granulomatosis with polyangiiti } \\
\text { GINA, global initiative for asthma; RA, rheumatoid arthritis. }{ }^{*} \text { GINA treatment step at the start of the study pe } \\
\text { riods. }{ }^{\dagger} \text { Oral corticosteroids used for reasons other than asthma were not included in evaluating the treatmen } \\
\text { step of asthma. }\end{array}$} \\
\hline
\end{tabular}

$22.5 \%$ of systemic corticosteroid use for reasons likely other than asthma was to control allergic diseases such as CRS and EGPA. These diseases have an etiology and treatment target in common with asthma. For example, dupilumab shows efficacy against both asthma and CRS [14-16]. Allergen immunotherapy is effective in allergic asthma and allergic rhinitis $[17,18]$. In addition, upperairway disease activity has an impact on asthma control and treatment of upper-airway diseases improves asthma control [19-21]. Biologics or immunotherapy might spare systemic corticosteroid used for asthma, by not only directly improving asthma control but also indirectly improving upper-airway disease control. With a view to reducing exposures to systemic corticosteroids, total management of allergic diseases is clearly important.

In this study, CVD was another main likely reason for systemic corticosteroid use. Among CVDs, RA is common in the general population and studies have shown an association between asthma and RA, with asthma increasing the risk of RA [22-24]. Some studies suggested that the air- 
Table 3. Main reason, dose, and duration of systemic corticosteroid use for likely nonasthma

\begin{tabular}{llllll}
\hline & $\begin{array}{l}\text { All, } \\
n(\%)\end{array}$ & $\begin{array}{l}\text { Short } \\
\text { high dose }\end{array}$ & $\begin{array}{l}\text { Short } \\
\text { low dose }\end{array}$ & $\begin{array}{l}\text { Long } \\
\text { high dose }\end{array}$ & $\begin{array}{l}\text { Long } \\
\text { low dose }\end{array}$ \\
\hline CVD & & & & & \\
RA & $9(7.5)$ & 2 & 0 & 1 & 8 \\
EGPA & $7(5.8)$ & 0 & 0 & 7 & 6 \\
Other & $24(20)$ & 2 & 2 & 19 & 12 \\
CRS & $20(16.7)$ & 5 & 13 & 3 & 3 \\
Malignancy & $12(10)$ & 9 & 1 & 1 & 1 \\
\hline
\end{tabular}

Main reasons $(n \geq 5)$ are presented. Some subjects received systemic corticosteroids for both long and short durations and/or at low and high doses. Dose of corticosteroid was categorized as low (prednisolone-equivalents $\leq 5 \mathrm{mg} /$ day) or high (prednisoloneequivalents $>5 \mathrm{mg} /$ day). Duration of systemic corticosteroid was categorized as short $(\leq 3$ months) or long (>3 months). CRS, chronic rhinosinusitis; CVD, collagen vascular disease; EGPA, eosinophilic granulomatosis with polyangiitis; RA, rheumatoid arthritis.
Table 4. Multivariable analysis for systemic corticosteroids use for likely nonasthma

\begin{tabular}{llr}
\hline & Odds ratio $(95 \% \mathrm{CI})$ & $p$ value \\
\hline Age & $1.02(1.00-1.04)$ & 0.033 \\
Sex & $0.64(0.39-1.05)$ & 0.072 \\
Follow-up period & $1.13(1.05-1.22)$ & 0.001 \\
RA & $3.42(1.30-8.98)$ & 0.017 \\
EGPA & $32.6(6.31-168)$ & $<0.001$ \\
Other CVD* & $22.8(9.04-52.3)$ & $<0.001$ \\
Allergic rhinitis & $0.66(0.36-1.20)$ & 0.165 \\
CRS & $4.97(2.64-9.36)$ & $<0.001$ \\
Malignancy & $8.56(3.15-23.2)$ & $<0.001$ \\
\hline
\end{tabular}

COPD, chronic obstructive pulmonary disease; CRS, chronic rhinosinusitis; CVD, collagen vascular disease; EGPA, eosinophilic granulomatosis with polyangiitis; RA, rheumatoid arthritis; CI, confidence interval. * EGPA and RA were excluded from other CVD.

way mucosal inflammation is related to anticitrullinated protein antibody production and seropositive RA development $[25,26]$. Zaccardelli et al. [26] reported anticitrullinated protein antibody elevation in asthma prior to RA diagnosis, suggesting that airway inflammation in asthma is also related to RA development. In fact, $3.9 \%$ of individuals with asthma in this study had RA, which seems higher than the rate in the general population [27]. Systemic steroids are also used for other CVDs, such as systemic lupus erythematosus. Asthma increases the risk of autoimmune diseases, including systemiclupuserythematosus andSjögren's syndrome [24]. In subjects with asthma, systemic corticosteroid use for CVD also requires attention.

Systemic Corticosteroids in Asthma
In the multivariable analysis, malignancy was another factor related to systemic corticosteroid use for reasons likely other than asthma. Systemic corticosteroids are used as anticancer agents (i.e., lymphoma) [28], antiemetics [29], and palliative care in oncology [30]. As cancer prognoses have improved [31], not only short-term but also long-term adverse events related to systemic corticosteroids require attention.

The prevalence of OCS use in general population is around $15 \%$ [32]. In this study, about $40 \%$ of subjects with asthma received systemic corticosteroids for reasons other than asthma. Compared to general population, subjects with asthma might have a higher risk of OCS exposure and require special attention.

This study has some limitations that require consideration when interpreting the results. First, the major limitation is the retrospective nature of the study. Neither diagnostic criteria for asthma nor timing of spirometry and blood test was predefined. Besides, some data are lacking. But the diagnosis of asthma was made by the pulmonologist and/or the allergist. In addition, the steroid prescription and the reason for prescription were recorded on an electronic chart. Thus, the data of systemic steroids' prescription are relatively firm. Second, this study was performed at a single university hospital. It could not be applicable to the asthma in general. However, this study included mild asthma (GINA step 1/2) and most of the comorbidities for which systemic corticosteroids were used were common diseases. Third, we could not clarify conditions of use for systemic corticosteroid prescribed at other hospitals and/or clinics. A greater proportion of subjects with asthma might thus be exposed to systemic corticosteroid use for reasons other than asthma. Fourth, 
recent advances in treatment for many fields might have allowed reductions in systemic corticosteroid use among subjects with asthma. Further study is needed in the future to clarify whether systemic corticosteroid use for reasons other than asthma is decreasing in subjects with asthma.

In conclusion, about $40 \%$ of subjects with asthma at a university hospital received at least 1 dose of systemic corticosteroids for reasons likely other than asthma during follow-up (median, 4.1 years). Clinicians should familiarize themselves with the exposure of their asthma patients to systemic corticosteroids for nonasthma uses, to avoid missing adverse events or underestimation of the severity of asthma, and to reduce the use of systemic corticosteroids.

\section{Statement of Ethics}

This research was conducted ethically in accordance with the World Medical Association Declaration of Helsinki. This study was approved by the institutional review board at Yokohama City University Hospital (approval no. B200500001). Due to the retrospective nature of this study, the need to obtain written informed consent was waived.

\section{Conflict of Interest Statement}

$\mathrm{K}$. Watanabe received research grants and/or lecture fees from AstraZeneca, KYORIN Pharmaceutical Co., Nippon Boehringer Ingelheim, and Novartis. N. Horita has nothing to declare. Y. Hara received research grants and/or lecture fees from AstraZeneca, GlaxoSmithKline, and Novartis. N. Kobayashi received research grants and/or lecture fees from AstraZeneca, GlaxoSmithKline, MSD, Nippon Boehringer Ingelheim, and Novartis. T. Kaneko received research grants and/or lecture fees from AstraZeneca, GlaxoSmithKline, KYORIN Pharmaceutical Co., Nippon Boehringer Ingelheim, and Novartis.

\section{Funding Sources}

There is no funding related to this article.

\section{Author Contributions}

K.W. contributed to the conception and design of the study; to the collection of patient data; to the analysis and interpretation of the data; and to drafting and finalizing the manuscript. N.H., Y.H., N.K., and T.K. contributed to the interpretation of the data and to finalizing the manuscript. All the authors have read and approved the final manuscript.

\section{Data Availability Statement}

All data generated or analyzed during this study are included in this article and its online suppl. files (for all online suppl. material, see www.karger.com/doi/10.1159/000518461). Further enquiries can be directed to the corresponding author.

\section{References}

1 Bleecker ER, Menzies-Gow AN, Price DB, Bourdin A, Sweet S, Martin AL, et al. Systematic literature review of systemic corticosteroid use for asthma management. Am J Respir Crit Care Med. 2020 Feb;201(3):276-93.

2 Price D, Castro M, Bourdin A, Fucile S, Altman P. Short-course systemic corticosteroids in asthma: striking the balance between efficacy and safety. Eur Respir Rev. 2020 Apr; 29(155):190151.

3 Waljee AK, Rogers MA, Lin P, Singal AG, Stein JD, Marks RM, et al. Short term use of oral corticosteroids and related harms among adults in the United States: Population Based Cohort Study. BMJ. 2017 Apr;357:j1415.

4 Sullivan PW, Ghushchyan VH, Globe G, Schatz M. Oral corticosteroid exposure and adverse effects in asthmatic patients. J Allergy Clin Immunol. 2018 Jan;141(1):110-6.e7.

5 Daugherty J, Lin X, Baxter R, Suruki R, Bradford $\mathrm{E}$. The impact of long-term systemic glucocorticoid use in severe asthma: a UK retrospective cohort analysis. J Asthma. 2018 Jun; 55(6):651-8.
6 Ekström M, Nwaru BI, Hasvold P, Wiklund F, Telg G, Janson C. Oral corticosteroid use, morbidity and mortality in asthma: a Nationwide Prospective Cohort Study in Sweden. Allergy. 2019 Nov;74(11):2181-90.

7 Schatz M, Rosenwasser L. The allergic asthma phenotype. J Allergy Clin Immunol Pract. 2014 Nov-Dec;2(6):645-9.

8 Tran TN, King E, Sarkar R, Nan C, Rubino A, O'Leary C, et al. Oral corticosteroid prescription patterns for asthma in France, Germany, Italy and the UK. Eur Respir J. 2020 Jun;55(6): 1902363.

9 Lommatzsch M, Sauerbeck IS, Wilmer C, Taube C. Oral corticosteroid prescription for asthma by general practitioners: a three-year analysis in Germany. Respir Med. 2021 Jan; 176:106242

10 Tran TN, MacLachlan S, Hicks W, Liu J, Chung Y, Zangrilli J, et al. Oral corticosteroid treatment patterns of patients in the United States with persistent asthma. J Allergy Clin Immunol Pract. 2021 Jan;9(1): 338-46.e3.
11 Chipps BE, Haselkorn T, Paknis B, Ortiz B, Bleecker ER, Kianifard F, et al. More than a decade follow-up in patients with severe or difficult-to-treat asthma: the epidemiology and natural history of asthma: outcomes and treatment regimens (TENOR) II. J Allergy Clin Immunol. 2018 May;141(5):1590-7.e9.

12 Ohta K, Bousquet PJ, Aizawa H, Akiyama K, Adachi M, Ichinose M, et al. Prevalence and impact of rhinitis in asthma. SACRA, a CrossSectional Nation-Wide Study in Japan. Allergy. 2011 Oct;66(10):1287-95.

13 Okayama $Y$, Matsumoto $H$, Odajima $H$, Takahagi S, Hide M, Okubo K. Roles of omalizumab in various allergic diseases. Allergol Int. 2020 Apr;69(2):167-77.

14 Castro M, Corren J, Pavord ID, Maspero J, Wenzel S, Rabe KF, et al. Dupilumab efficacy and safety in moderate-to-severe uncontrolled asthma. N Engl J Med. 2018 Jun; 378(26):2486-96. 
15 Rabe KF, Nair P, Brusselle G, Maspero JF, Castro M, Sher L, et al. Efficacy and safety of dupilumab in glucocorticoid-dependent severe asthma. N Engl J Med. 2018 Jun;378(26): 2475-85.

16 Bachert C, Han JK, Desrosiers M, Hellings PW, Amin N, Lee SE, et al. Efficacy and safety of dupilumab in patients with severe chronic rhinosinusitis with nasal polyps (LIBERTY NP SINUS-24 and LIBERTY NP SINUS-52): results from two multicentre, randomised, double-blind, placebo-controlled, parallelgroup phase 3 trials. Lancet. 2019 Nov; 394(10209):1638-50.

17 Zhang W, Lin C, Sampath V, Nadeau K. Impact of allergen immunotherapy in allergic asthma. Immunotherapy. 2018 Jun; 10(7): 579-93.

18 Durham SR, Penagos M. Sublingual or subcutaneous immunotherapy for allergic rhinitis? J Allergy Clin Immunol. 2016 Feb;137(2): 339-49.e10.

19 Brożek JL, Bousquet J, Agache I, Agarwal A, Bachert C, Bosnic-Anticevich S, et al. Allergic rhinitis and its impact on asthma (ARIA) guidelines - 2016 revision. J Allergy Clin Immunol. 2017 Oct;140(4):950-8.
20 Rosati MG, Peters AT. Relationships among allergic rhinitis, asthma, and chronic rhinosinusitis. Am J Rhinol Allergy. 2016 Jan-Feb; 30(1):44-7.

21 Porsbjerg C, Menzies-Gow A. Co-morbidities in severe asthma: clinical impact and management. Respirology. 2017 May;22(4):651-61.

22 Sheen YH, Rolfes MC, Wi CI, Crowson CS, Pendegraft RS, King KS, et al. Association of asthma with rheumatoid arthritis: a Population-Based Case-Control Study. J Allergy Clin Immunol Pract. 2018 Jan-Feb;6(1):219-26.

23 Ford JA, Liu X, Chu SH, Lu B, Cho MH, Silverman EK, et al. Asthma, chronic obstructive pulmonary disease, and subsequent risk for incident rheumatoid arthritis among women: a Prospective Cohort Study. Arthritis Rheumatol. 2020 May;72(5):704-13.

24 Krishna MT, Subramanian A, Adderley NJ, Zemedikun DT, Gkoutos GV, Nirantharakumar K. Allergic diseases and long-term risk of autoimmune disorders: Longitudinal Cohort Study and cluster analysis. Eur Respir J. 2019 Nov;54(5):1900476.

25 Holers VM, Demoruelle MK, Kuhn KA, Buckner JH, Robinson WH, Okamoto Y, et al. Rheumatoid arthritis and the mucosal origins hypothesis: protection turns to destruction. Nat Rev Rheumatol. 2018 Sep;14(9):542-57.
26 Zaccardelli A, Liu X, Ford JA, Cui J, Lu B, Chu $\mathrm{SH}$, et al. Asthma and elevation of anti-citrullinated protein antibodies prior to the onset of rheumatoid arthritis. Arthritis Res Ther. 2019 Nov;21(1):246.

27 Smolen JS, Aletaha D, McInnes IB. Rheumatoid arthritis. Lancet. 2016 Oct;388(10055): 2023-38.

28 Pufall MA. Glucocorticoids and cancer. Adv Exp Med Biol. 2015;872:315-33.

29 Navari RM, Aapro M. Antiemetic prophylaxis for chemotherapy-induced nausea and vomiting. N Engl J Med. 2016 Apr;374(14):1356-67.

30 Jaward LR, O’Neil TA, Marks A, Smith MA. Differences in adverse effect profiles of corticosteroids in palliative care patients. Am J Hosp Palliat Care. 2019 Feb;36(2):158-68.

31 Kawabata-Shoda E, Charvat H, Ikeda A, Inoue M, Sawada N, Iwasaki M, et al. Trends in cancer prognosis in a population-based cohort survey: can recent advances in cancer therapy affect the prognosis? Cancer Epidemiol. 2015 Feb;39(1):97-103.

32 Bénard-Laribière A, Pariente A, Pambrun E, Bégaud B, Fardet L, Noize P. Prevalence and prescription patterns of oral glucocorticoids in adults: a retrospective cross-sectional and cohort analysis in France. BMJ Open. 2017 Jul;7(7):e015905. 